\title{
Analyzing Parametric Sensitivity on the Cyclic Behavior of Steel Shear Walls
}

\author{
Seyed Mohamad Seyed Kolbadi ${ }^{1},{ }^{1}$ Nemat Hassani, ${ }^{2}$ Seyed Mahdi Seyed-Kolbadi, ${ }^{3}$ \\ and Masoud Mirtaheri ${ }^{3}$ \\ ${ }^{1}$ Department of Civil Engineering, Technical and Vocational University (TVU), Tehran, Iran \\ ${ }^{2}$ Department of Civil, Water \& Environmental Engineering, Shahid Beheshti University, Tehran, Iran \\ ${ }^{3}$ Department of Civil Engineering, KN Toosi University of Technology, Tehran, Iran \\ Correspondence should be addressed to Seyed Mohamad Seyed Kolbadi; s_seyyedkolbadi@sbu.ac.ir
}

Received 31 May 2021; Revised 1 July 2021; Accepted 30 October 2021; Published 28 November 2021

Academic Editor: Shan Gao

Copyright (c) 2021 Seyed Mohamad Seyed Kolbadi et al. This is an open access article distributed under the Creative Commons Attribution License, which permits unrestricted use, distribution, and reproduction in any medium, provided the original work is properly cited.

\begin{abstract}
As a destructive phenomenon in most parts of the world, earthquake has threatened the safety of structures and the lives of its inhabitants and is considered as the main problem in the seismic vulnerability of buildings. Steel shear walls are regarded as one of the newest structural systems resistant to lateral load in steel structures. The present study aimed to investigate the impact of effective parameters on cyclic behavior by numerically modeling a steel shear wall and comparing it with laboratory results. The results indicated the significant contribution of the thickness of steel shear sheet so that when the thickness changes to $25 \%$, the final response of the structure increased by approximately $20 \%$ and decreased by $15 \%$.
\end{abstract}

\section{Introduction}

As a destructive phenomenon in most parts of the world, earthquake has threatened the safety of structures and the lives of its inhabitants; reducing the irreparable damage of earthquakes has always been the ultimate goal of researchers and scientists in earthquake engineering. The probability of an earthquake based on the distribution of active faults in Iran in Figure 1 indicates a permanent danger. Researchers have introduced various earthquake-resistant lateral-bearing systems over time. This process has continued from the frames of building materials to introducing the structural control systems. The steel shear wall system (Figure 2) is considered as one of the new seismic systems, which has been approved by the Canadian Steel Code since 1994 and has been recognized by the US Steel Code since 2005. As a destructive phenomenon in most parts of the world, earthquake has threatened the safety of structures and the lives of its inhabitants; reducing the irreparable damage of earthquakes has always been the ultimate goal of researchers and scientists in earthquake engineering. The probability of an earthquake based on the distribution of active faults in Iran in Figure 1 indicates a permanent danger. Various earthquake-resistant lateral-bearing systems have been introduced by researchers over time. This process has continued from the frames of building materials to introducing the structural control systems. The steel shear wall system (Figure 2) is considered as one of the new seismic systems which has been approved by the Canadian Steel Code since 1994 and has been recognized by the US Steel Code since 2005.

During recent years, when the research on the seismic performance of steel shear walls and their reliability is increased, using these walls, especially in the United States and Japan, has increased significantly [1]. The design regulations have now begun to provide design criteria for such walls due to the relatively comprehensive knowledge of their behavior. The basis of the performance of this structural system is based on using the performance of the diagonal tensile field after buckling of steel sheets. The simple implementation based only on existing technical knowledge and without the need to acquire new skills 


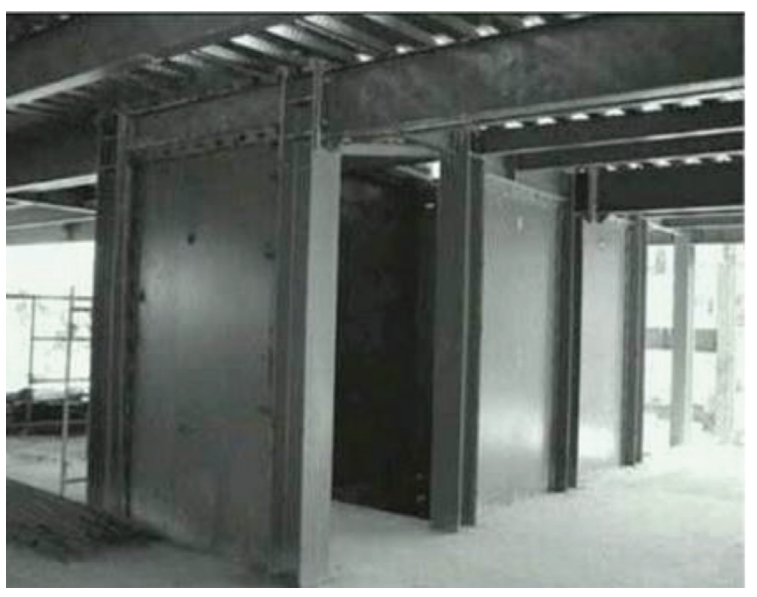

FIgUre 1: Executing steel shear wall.

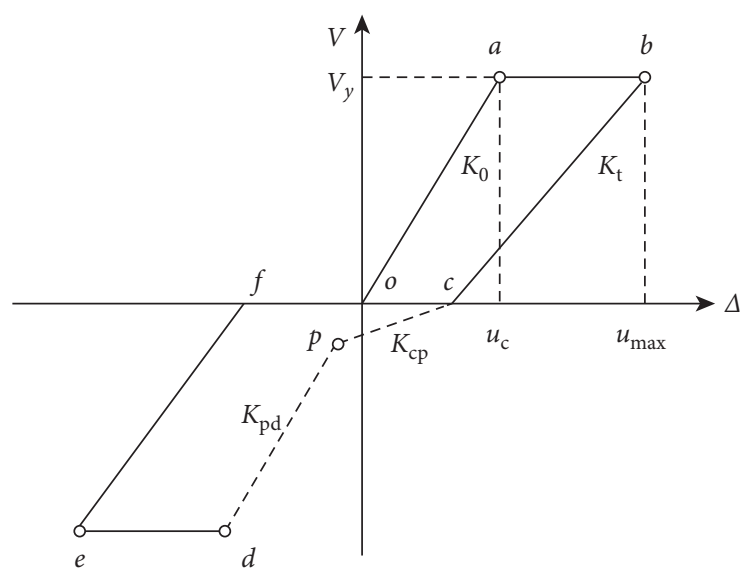

FIGURE 2: Steel shear wall pinching hysteresis curve.

reduced dimensions of the foundation, significantly increases the lateral stiffness of the structure, and reduced dead load, while the economics of this system compared to the steel bending frame system is considered as the main advantages of this system [2].

At first glance, a steel shear wall is similar to a sheet beam, in which the beams, the columns, and the steel sheet act as stiffeners, wings, and the core of the sheet beam, respectively. At the beginning of using such shear walls, the steel sheet was used with hardener and tried to prevent the sheet from buckling. However, researchers further suggest the use of thin-walled steel shear walls without hardeners based on the experiments today. The loading of the sheet buckles in the compression diameter and flows in the tensile diameter, and the buckling diameter returns to the sheet plate during the loading and becomes the tensile diameter [3]. At this distance, the resistance of the sample decreases and pinching occurs in the hysteresis curve. Figure 2 shows the pinching situation in the distance between points C and D. Despite the sheet buckling, the steel shear wall system is still stable, and it is not necessary to use hardener to create and maintain the stability of the system and prevent buckling [4].

Timler and Kulak [5] performed circular tests on steel shear walls without hardeners. It was found that the buckling behavior of the sheet is well shown, which resulted in the ductility coefficient $\mu$ as 4 . They were a model of diagonal rod elements replacing steel sheet, which was well predicted for a cyclic loading of experimental behavior. Driver et al. [6] performed a cyclic experiment on a four-story sample. In this experiment, the steel shear wall was without hardener, and the ductility coefficient $\mu$ of 6 was obtained. In addition, they presented an analytical model in which a steel sheet was modeled with a shell element and the geometric and material nonlinear behaviors were considered. The results of computer analysis of their model did not indicate good accuracy. They finally concluded that the steel shear wall system has a high ductility. Lubell et al. [7] performed cyclic experiments on a four-story sample and two one-story samples. Their samples were hardener free. They obtained a ductility coefficient $\mu$ of 6 from the test results. Elgaaly and Liu [8] performed cyclic experiments on six three-story specimens with an aperture in which the steel sheet was hardener free. They found that the nonlinear behavior of the system initiated with the flow of steel in the sheet and the resistance of the system was controlled by forming a plastic joint in the column. That is, they recommended that the wall sheet be completely flowing before buckling the column.

Furthermore, Astaneh-Asl [9] performed cyclic experiments on steel shear walls. The steel sheet in these experiments was without using the hardeners. He concluded that the steel shear after rupture could withstand $60 \%$ of the tolerable force before rupture in the joints. This is especially useful in the event of a severe earthquake. Because the steel shear wall system is still able to withstand lateral load after rupture. Rahaei and Hatami conducted their research on composite steel shear wall in gap mode under cyclic loads. They concluded with numerical and laboratory studies that increasing the distance between the bolts to a certain extent increases the energy absorption power and reduces the offplane displacement and the maximum normal stress in the cutters; however, the distances longer than this have little effect. In addition, the behavior of reinforced steel shear wall is independent of the stiffness of the middle beams and the type of connection of the beam to the column; however, increasing the stiffness of the beam in shear walls without hardeners causes better uniformity of stress distribution in steel sheet and finally shear strength of steel shear wall. The compound has a direct ratio with the thickness of the concrete cover and an inverse ratio with the distance between the cutters [10].

Astana-Asl and Zhao conducted an experiment on a composite shear wall at the University of Berkeley, California, in which the behavior of a new type of wall under reciprocating loads was investigated and compared with the behavior of a traditional composite shear wall. The only difference between the shear wall of the new type and the traditional model was the existence of a gap between the concrete wall and the perimeter frame in the new model. Both systems showed ductile behavior and high resistance during the experiment. Observing the results of this experiment, they found that although using the gaps reduces the overall strength and stiffness (due to the lack of concrete participation in low loads), this reduction is acceptable and 
is less important compared to increasing the ductility and reducing the damage to concrete due to existing such gap [11]. Hatami and Sehri conducted a study on composite steel shear walls titled investigating steel sheet thickness on the behavior of composite steel shear walls and concluded that increasing the thickness of steel sheet to the concrete layer to the optimal thickness resulted in reducing the amount of displacement outside the plate of steel sheet and did not further affect the performance of the shear wall. In addition, using two layers of concrete cover on both sides of the steel sheet to some extent reduces the secondary flexural effects [12].

Furthermore, Hadipour and Razaghi studied and compared the bearing capacity and ductility behavior of composite steel shear walls through the finite element method. They found that changing the distance between the cutters changes the ductility of the structure and the amount of energy absorption [13]. Some experiments were initiated to investigate the behavior of this lateral-bearing system for studying the behavior of steel shear wall. Takanashi and Takemoto and Mimura and Akiyama performed seismic (reciprocating) experiments on twelve one-story and two two-story samples $[14,15]$. Yamada performed experiments on two samples of a class under increasing load [2]. Caccese and Elgaaly performed experiments under seismic loading (reciprocating) on eight three-story and seven two-story samples in two stages [16].

\section{Materials and Methods}

Professor Pauli from New Zealand, who was one of the great seismic designers in the world and is credited with inventing the capacitive method in the design of structures, exemplifies the structure as several interlocking chains (Figure 3). He believed that it is definitely necessary to fit one of these rings intentionally weaker so that it enters the nonlinear area in the earthquake and causes the earthquake energy loss. To do this, two things should be considered. (A) The detailing in the weaker area should be such that it does not suffer from instability and deterioration in large deformations. (B) The rest of the chain loops should be designed in such a way that they have such resistance that they remain in the elastic region when the ductile ring reaches its resistance limit.

Ductility is a material that can deform greatly when resisting loads. The ductility of structural members means that they can withstand considerable inelastic or pasty deformation before collapsing. The fragile material or structure suddenly breaks and collapses under heavy loading. Figure 4 shows the force-deformation relationship for brittle and malleable materials.

The final deformation may be determined by the local failure of the compression zone at a point in the limb, or by instability, or by any other set of conditions leading to the failure of the limb or the related structure. The most common method of measuring ductility is the ductility ratio $(\mu)$, which is defined as follows [18]:

$$
\mu=\frac{\Delta u}{\Delta y} \text {. }
$$

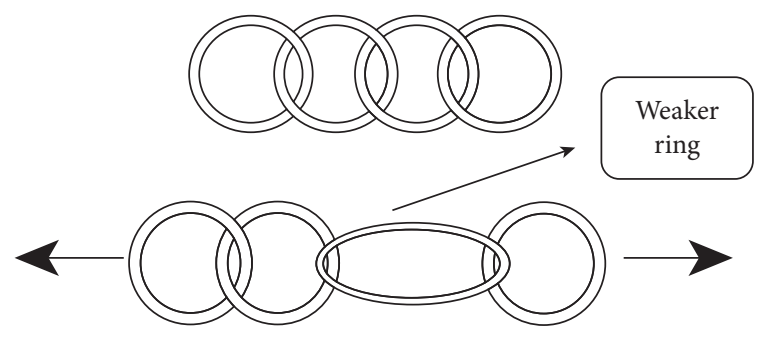

FIgURE 3: The concept of seismic design [17].
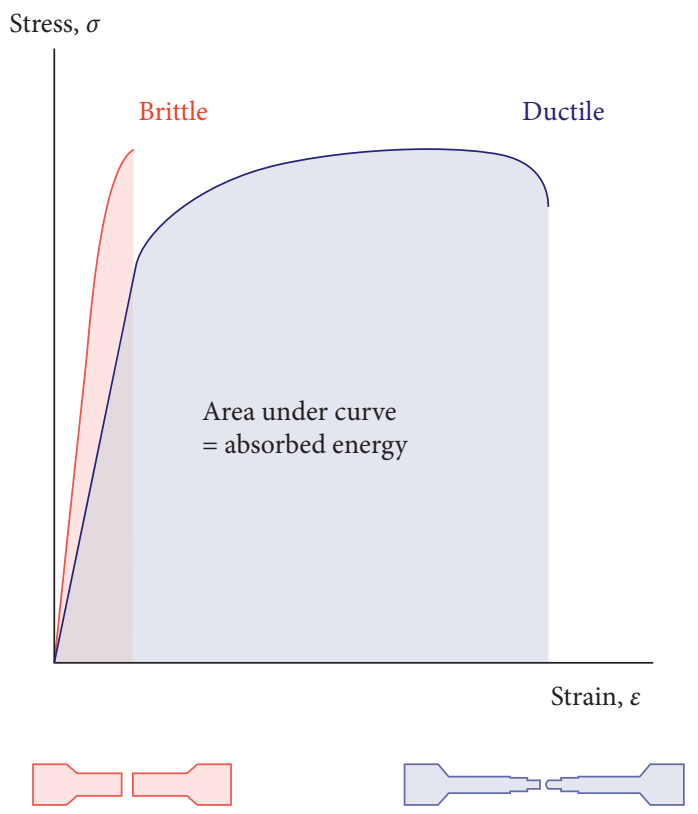

FIgURE 4: The behavior of fragile and ductile materials [17].

In the case of beams and bending elements, the ductility ratio is defined based on the curvature:

$$
\mu=\frac{\phi u}{\phi y} \text {. }
$$

The ductility of a member or structure is sometimes measured by the energy absorbed by it, which is determined by the area under the force-deformation curve. In addition, since the displacement capacity of the plastic under the reciprocating load is different from the capacity of the ascending load in the case of periodic loading, the ductility ratio is considered as the ratio of the total value of the displacement according to the following equation and Figure 5 [19]:

$$
\mu_{\delta}=\frac{\left|+\Delta_{\max }\right|+\left|-\Delta_{\text {min }}\right|}{\left|+\Delta_{y}\right|+\left|-\Delta_{y}\right|} .
$$

\section{Numerical Model}

3.1. Variable's Parameters. The powerful Abacus software based on the finite element numerical method has been used due to the complexity of solving nonlinear equations 


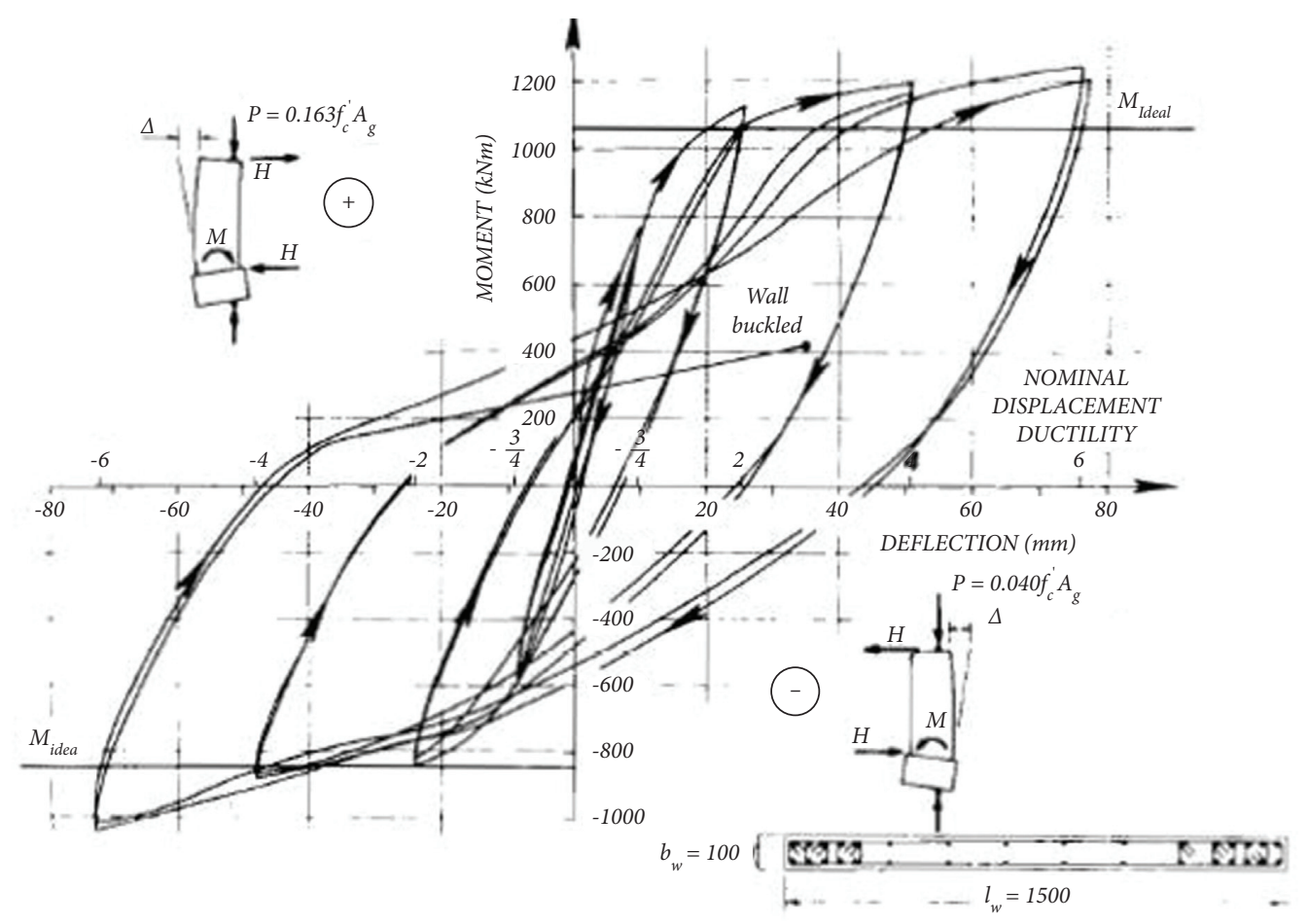

FIgURE 5: Definition of ductility considering positive and negative directions [19].

resulted from nonlinearity of materials (the nonlinear behavioral model of steel) and geometric nonlinearity (buckling of steel shear wall sheet). Furthermore, the eccentric random buckling was used as a construction error (imperfection) to reduce the computation time. In addition, performing sensitivity analysis on basic mechanical and geometric parameters resulted in realizing the impact of these parameters on the cyclic behavior of steel shear wall. Table 1 shows the amount of shear sheet, beam, and column changes.

3.2. Material Specifications. Nonlinear behavior with kinematic stiffness is selected for all samples. The plastic behavior of the model is selected based on Van Meiss flow rate and ST37 stress-strain diagram. According to Figure 6, Young's modulus and Poisson's coefficient are considered to be 0.3 [20].

3.3. Geometrical Specifications. The examined shear wall was $240 * 280 \mathrm{~cm}$. Furthermore, beams and columns were modeled from box sections of $10 * 15 \mathrm{~cm}$. The middle sheet of the wall was considered as a thickness of $1 \mathrm{~mm}$, which is variable according to Table 2 .

As shown in Figure 7, the standard Shell library element is used. Since the shape is geometrically irregular or applying the appropriate partitions divides it into regular shapes to obtain a regular meshing pattern, therefore, creating a meshing with four-node rlement Shape, the structured technique, the Standard library element from the Shell family, and finally the selected S4R element are used (Figure 8).
3.4. Loading. The seismic performance is a connection to the concept of the amount and distribution of stress values, ductility, and how to dissipate seismic energy. In this regard, the hysteresis diagrams was used which show this very well. It seems more appropriate to consider the period to choose a comprehensive loading pattern for the mentioned connection, which is applied to the boundary conditions of the end of the beam. In this regard, the seismic loading protocol was introduced by FEMA (Figure 9).

\section{Analyzing the Results}

4.1. Validation. In 2017, HajiMirsadeghi et al. [22] at Khajeh Nasir al-Din Tusi University of Technology loaded the steel shear wall back and forth in the laboratory with the same dimensions as the numerical model (Figure 10). The results of numerical modeling in cycles 1 to 17 with a slight difference corresponded to the laboratory results. Therefore, the accuracy of the results can be fully trusted (Figure 11).

4.2. The Cyclic Analysis of Shear Wall. A proper understanding of hysteresis behavior is required to evaluate the seismic behavior of a steel shear wall. Therefore, the cyclic behavior of the frame was investigated through the standard loading of FEMA Figure 9. Therefore, the displacement input to the frame tip was considered as input and the base shear force as output. However, anchor-anchor diagrams have been used to enable the comparison of diagrams with other frames. Figure 12 shows the plastic strain contour in 8 steps. 
TABLE 1: Variable parameters examined in the analysis (continued).

\begin{tabular}{|c|c|c|c|c|c|c|c|}
\hline \multicolumn{5}{|c|}{ ST12 (shear plate) } & \multicolumn{3}{|c|}{ ST37 (beam box and column box) } \\
\hline Num & Density $\left(\mathrm{kg} / \mathrm{m}^{3}\right)$ & Elastic $(\mathrm{GPa})$ & Plastic stress $\left(\mathrm{kN} / \mathrm{m}^{2}\right)$ & Thickness $(\mathrm{mm})$ & Density $\left(\mathrm{kg} / \mathrm{m}^{3}\right)$ & Elastic $(\mathrm{GPa})$ & Plastic stress $\left(\mathrm{kN} / \mathrm{m}^{2}\right)$ \\
\hline 1 & 7850 & 0.2 & 182 & 1 & 7850 & 0.2 & 240 \\
\hline 2 & 7850 & 0.25 & 182 & 1 & 7850 & 0.2 & 240 \\
\hline 3 & 7850 & 0.15 & 182 & 1 & 7850 & 0.2 & 240 \\
\hline 4 & 7850 & 0.2 & 227 & 1 & 7850 & 0.2 & 240 \\
\hline 5 & 7850 & 0.2 & 136 & 1 & 7850 & 0.2 & 240 \\
\hline 6 & 7850 & 0.2 & 182 & 1.25 & 7850 & 0.2 & 240 \\
\hline 7 & 7850 & 0.2 & 182 & 0.75 & 7850 & 0.2 & 240 \\
\hline 8 & 7850 & 0.2 & 182 & 1 & 7850 & 0.25 & 240 \\
\hline 9 & 7850 & 0.2 & 182 & 1 & 7850 & 0.15 & 240 \\
\hline 10 & 7850 & 0.2 & 182 & 1 & 7850 & 0.2 & 300 \\
\hline 11 & 7850 & 0.2 & 182 & 1 & 7850 & 0.2 & 180 \\
\hline
\end{tabular}

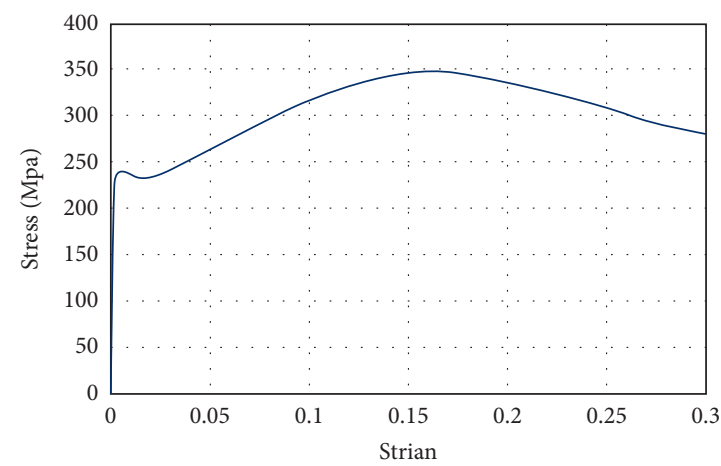

Figure 6: Nonlinear behavioral model of steel [20].

TABLE 2: The geometric characteristics of beams and columns.

\begin{tabular}{lccc}
\hline Element & Dimensions $(\mathrm{cm})$ & Thickness $(\mathrm{mm})$ & ${\text { Flow stress }\left(\mathrm{N} / \mathrm{mm}^{2}\right)}^{2}$ \\
\hline Beam & $10 * 15$ & 6 & 240 \\
Column & $10 * 15$ & 7 & 240 \\
\hline
\end{tabular}
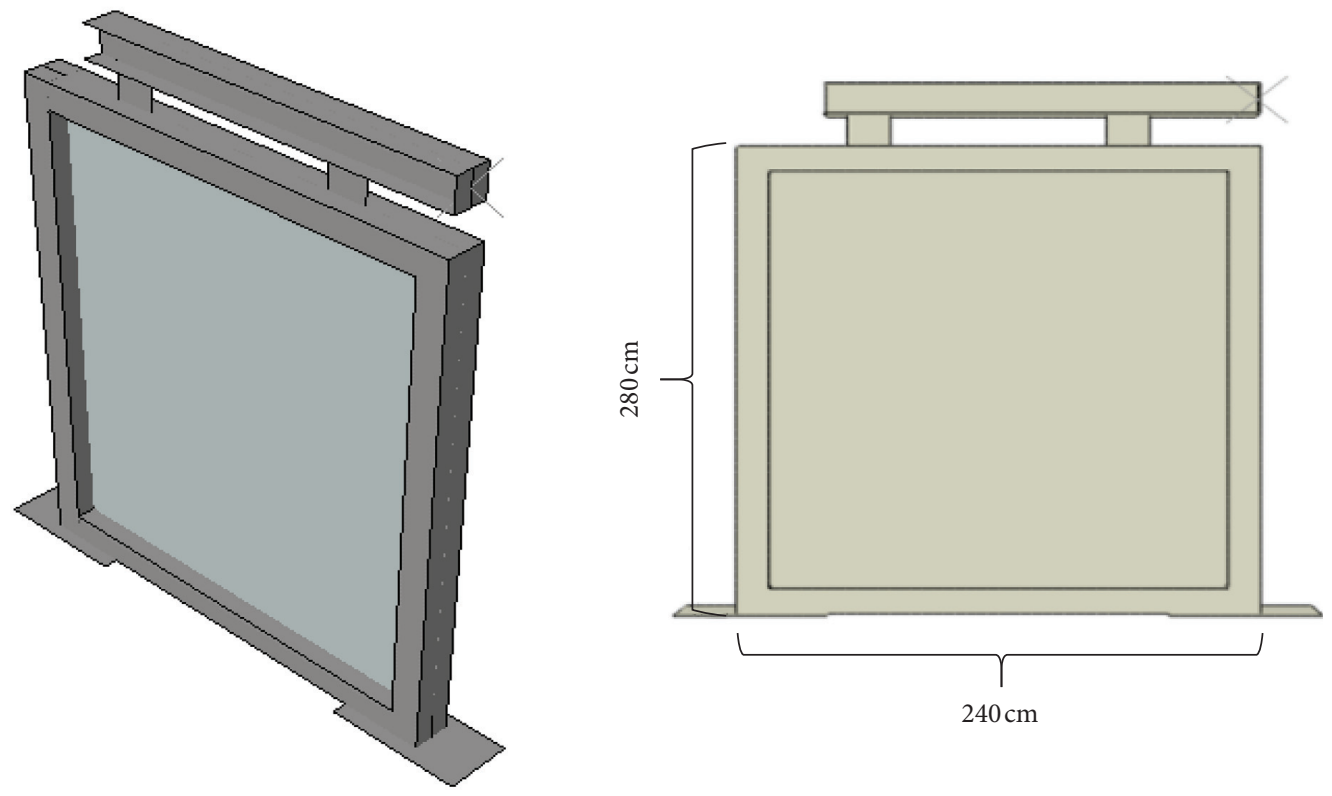

Figure 7: General dimensions of steel shear wall mode. 

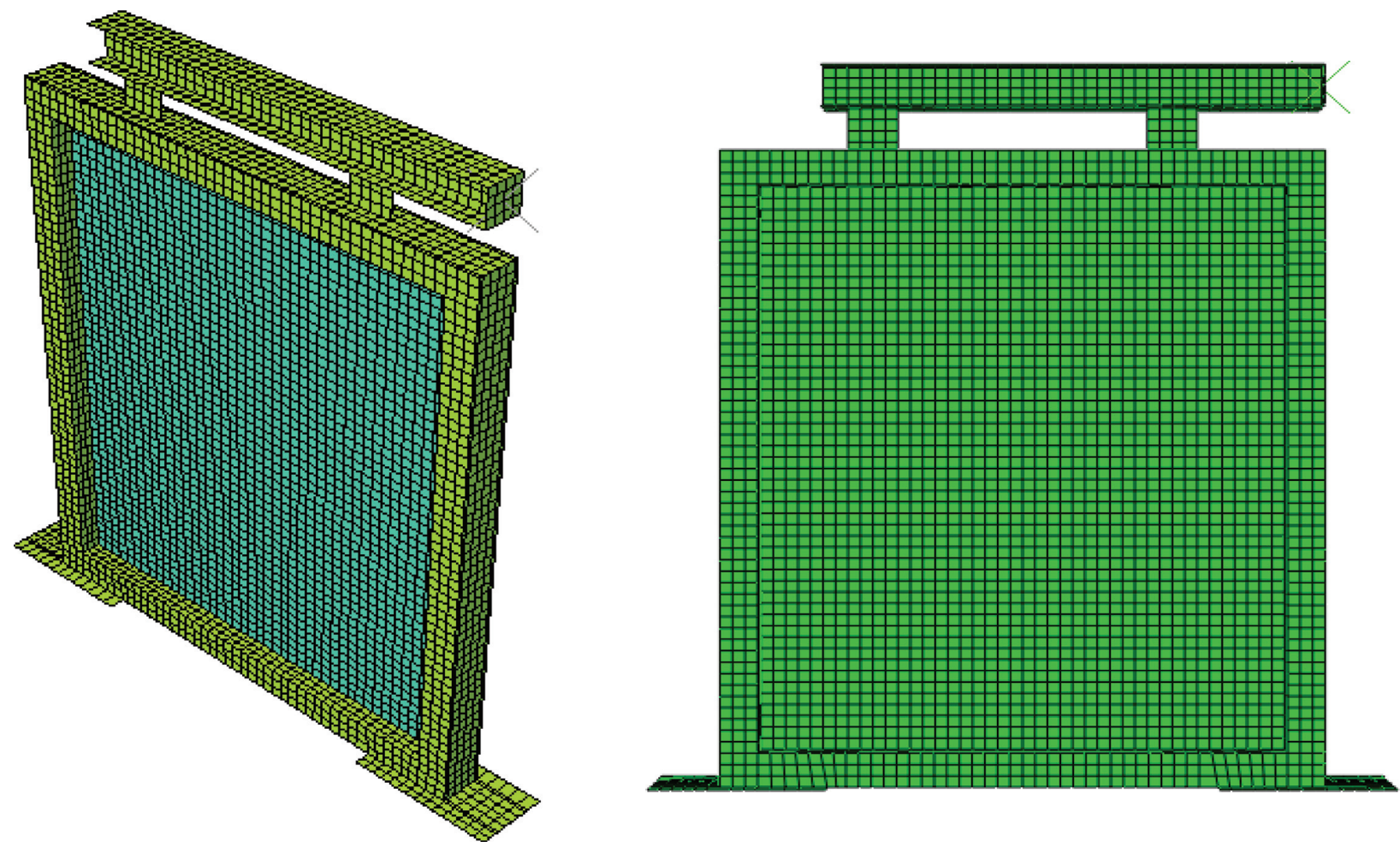

Figure 8: Numerical model meshing.

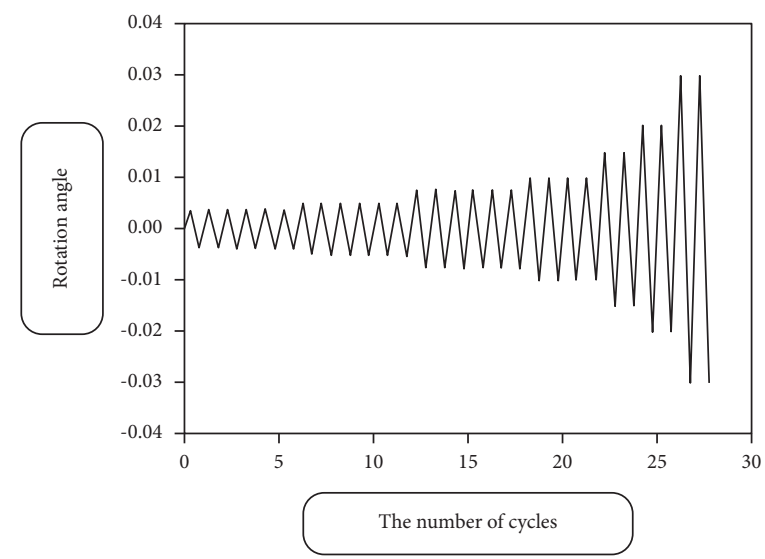

FIgURE 9: FEMA-350 loading pattern [21].
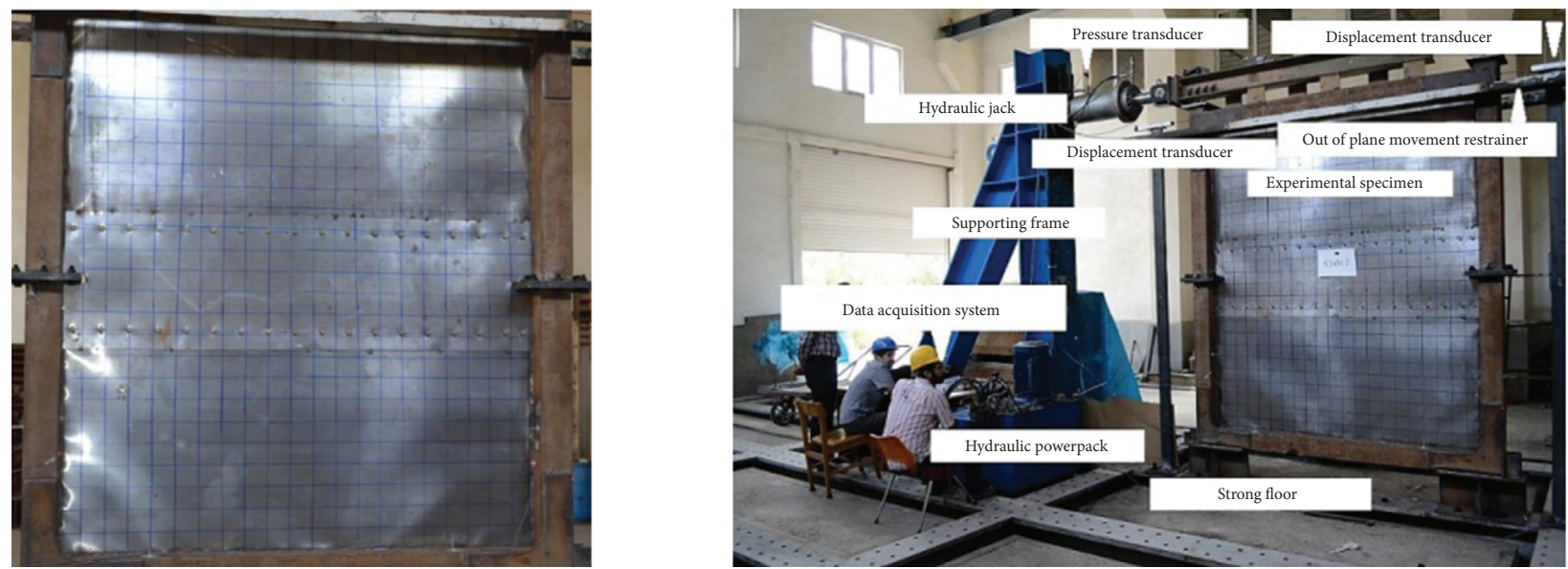

Figure 10: An overview of the laboratory model [22]. 


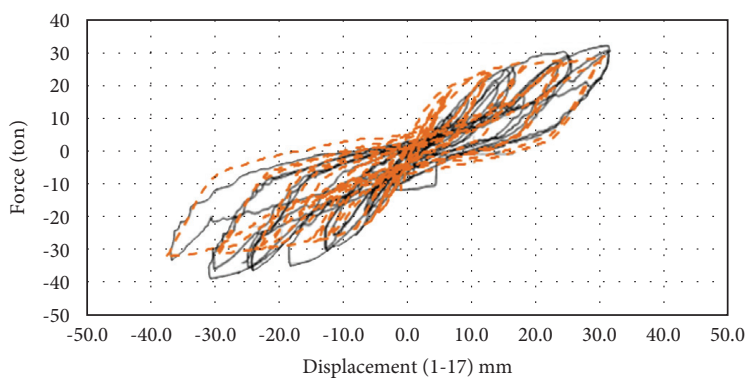

FIGURE 11: An overview of the laboratory model [22].
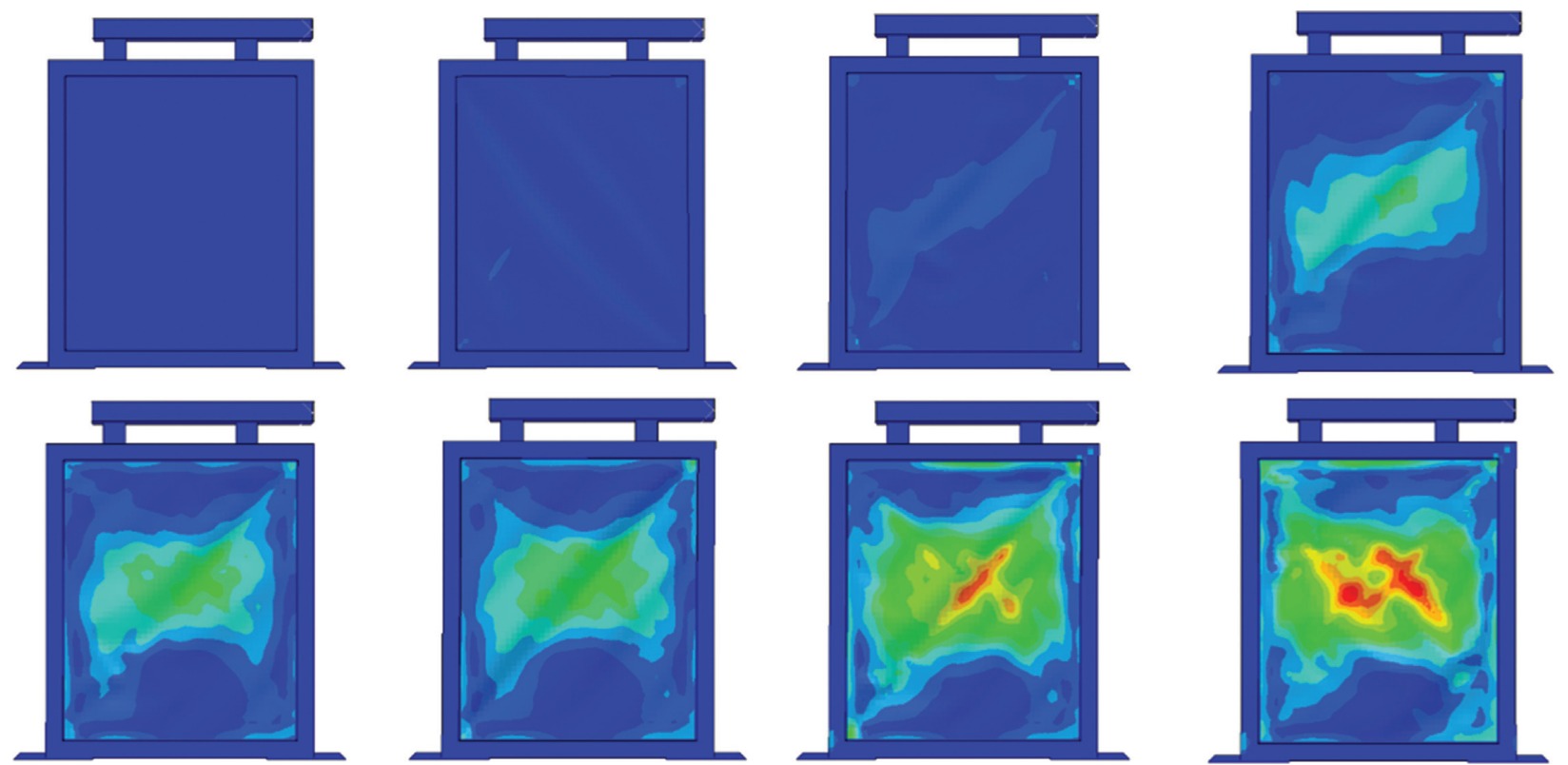

Figure 12: The plastic strain contour in 8 steps for shear wall under cyclic load of the laboratory model.

4.3. Investigating the Effect of Geometric and Mechanical Characteristics of Shear Wall Elements. According to Table 2, model No. 1 is considered as the base model, and other samples in sensitive parameters such as modulus of elasticity, plastic stress, and sheet thickness have about $25 \%$ of the amount changes (increase and decrease). Then, it was analyzed during standard cyclic loading, and the diagrams of hysteresis and plastic strain contour were obtained, as shown in Figure 13. According to the National Regulations of the Tenth Building, the increase value is about $25 \%$ of the values to provide the final increase coefficient of steel sheets in the event of an earthquake [23]. This increase is about $15 \%$ strength for rolled beams. In this study, $25 \%$ of the values are considered to compare the effective parameters of increase and decrease. The results of the hysteresis diagrams are shown in Figure 13.

The anchor-rotation diagram was used as a displacement-control method to compare the effect of changes in the effect quantities on the shear wall strength. As shown in Figure 13, changes in shear wall quantities such as thickness and plastic shear stress have a greater effect on shear wall strength than that of beam and column quantities. The comparison chart of Figure 14 was used to compare the changes slightly.

According to Figure 14, the changes in the thickness and type of sheet (plastic stress) have a significant impact on the 


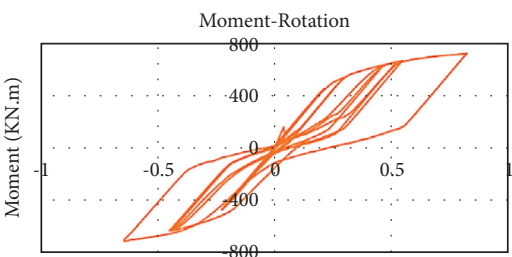

Rotation \% (Radian)

Sample No.3

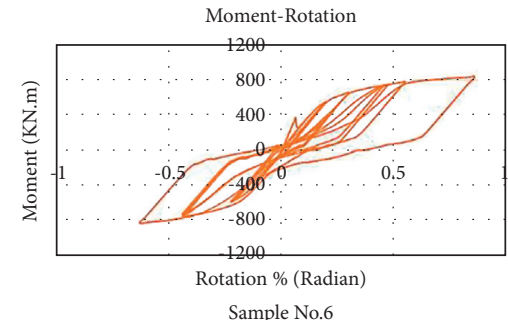

Sample No.6

Moment-Rotation

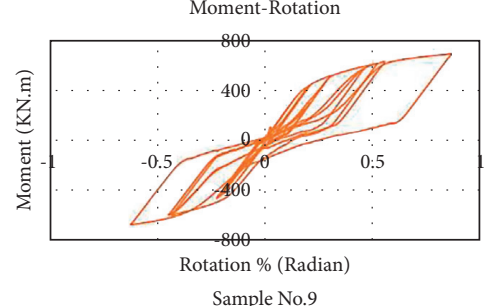

Moment-Rotation

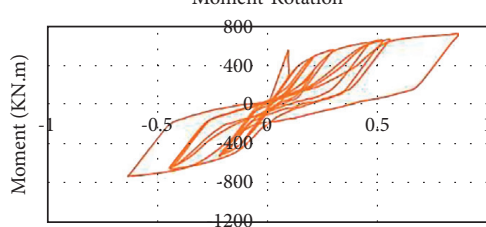

Rotation \% (Radian)

Sample No. 2

Moment-Rotation

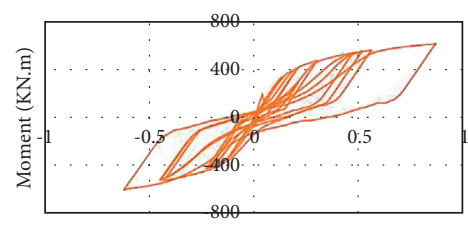

Rotation \% (Radian) Sample No.5

Moment-Rotation

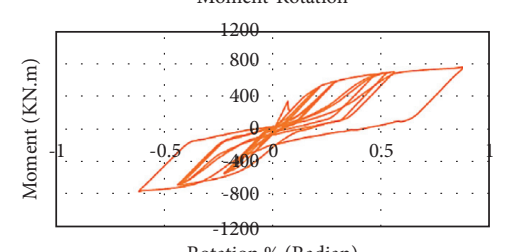

Rotation \% (Radian)

Sample No.8

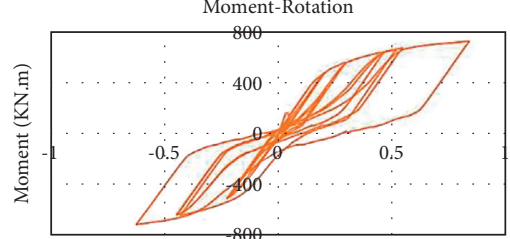

Rotation \% (Radian)

Sample No.1

Moment-Rotation

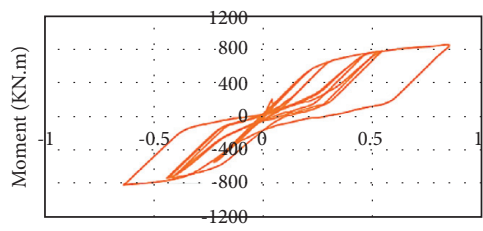

Rotation \% (Radian) Sample No.4

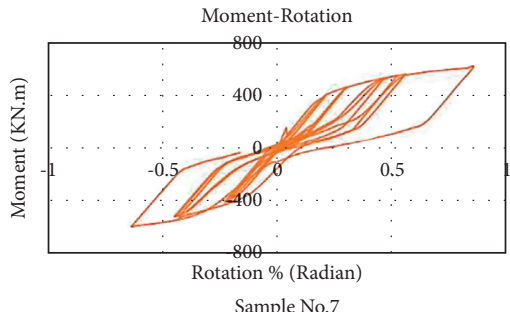

Sample No.7

Moment-Rotation

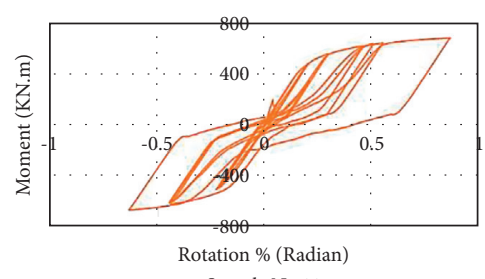

Sample No.11

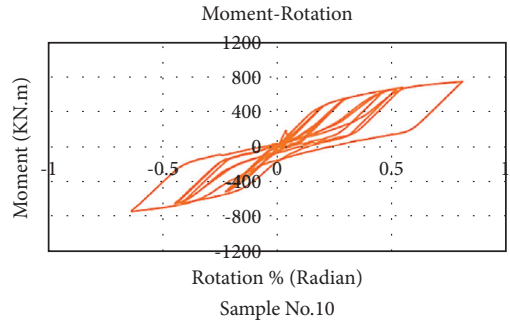

Figure 13: Anchor-period hysteresis diagram in the first 17 cycles for samples 1 to 11 . 


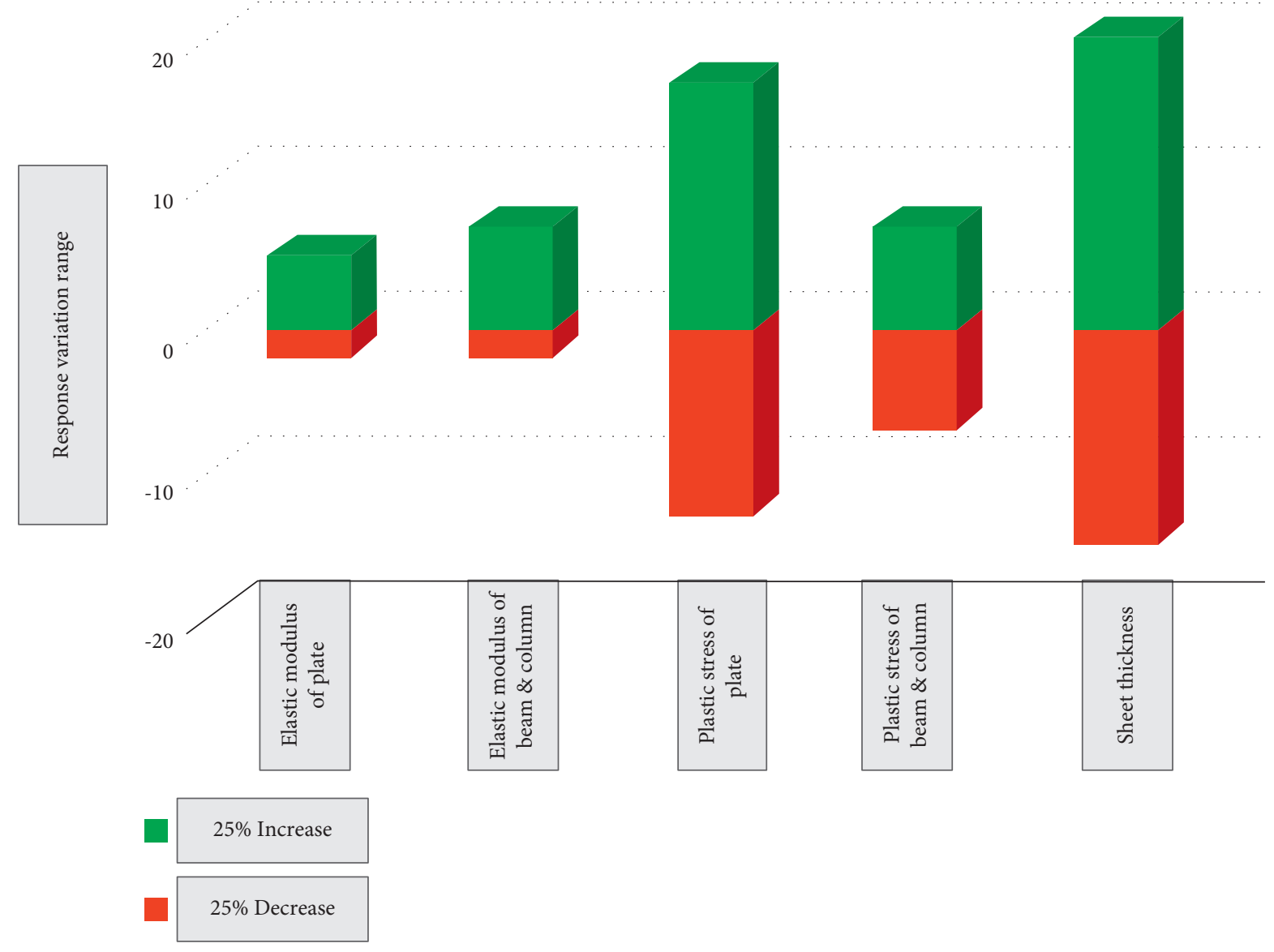

Figure 14: Comparing the effect of changes in effect quantities on shear wall strength.

strength of the structure. On an average, an increase and decrease of $25 \%$ in the thickness and tension values of the plastic sheet by $18 \%$ and $15 \%$, respectively, had an effect on the shear wall strength.

\section{Conclusion}

When the amount of modulus of elasticity of the sheet (frames 2 and 3) increases by 25\%, the final strength of the shear wall increases by about $5 \%$ and by decreasing by $25 \%$ of the same amount, the response rate decreases by $2 \%$. Therefore, the linear area of the shear sheet has little effect on the final behavior of the frame. This is due to increasing the stress in low periods, and therefore, the plastic area can be the determining factor in the final behavior of the structure. The behavior of the structure is similar to the behavior of structures 2 and 3 by increasing and decreasing the elasticity modulus of beams and columns by $25 \%$ (frames 8 and 9), which increases and decreases by $7 \%$ and $2 \%$, respectively, which are trivial amounts.
In addition, the amount of plastic stress of the shear sheet was evaluated. When this value increases by $25 \%$, the final strength of the frame increases by about $17 \%$, and when the plastic stress of the sheet decreases by $25 \%$, the final response of the frame decreases by about $13 \%$. These values indicate a significant effect of the amount of plastic stress intended for the shear sheet. If $25 \%$ changes is considered for the beam and column plastic stress parameter, the final strength values of the frame will increase and decrease by about $7 \%$ and $7 \%$, respectively. That is, the effect of the plastic stress parameter of the column beam does not play a significant role in the strength and behavior of the frame; however, the same parameter have a significant effect on the shear sheet.

The last parameter is the thickness of the shear sheet. When the thickness value changes by $25 \%$, the final response of the structure increased and decreased by about $20 \%$ and $15 \%$, respectively, indicating the significant effect of sheet thickness on the behavior of the frame and ultimately the behavior of the structure. Furthermore, when the thickness 
of the sheet increases, the hysteresis diagram have a larger area under the diagram that has increased by about $20 \%$ compared to the base state and therefore indicates significant ductility and energy consumption. Comparing the results obtained in this article indicated the significant effect of shear sheet properties on the behavior of the frame. In addition, the changes in the mechanical properties of the beam and column on the frame behavior will not be significant because the shear sheet provides most of the lateral stiffness of the frame.

\section{Data Availability}

The data used to support the findings of the study are available from the corresponding author upon request.

\section{Conflicts of Interest}

The authors declare that there are no conflicts of interest regarding the publication of this paper.

\section{References}

[1] M. Elgaaly, "Thin steel plate shear walls behavior and analysis," Thin-Walled Structures, vol. 32, pp. 151-180, 2015.

[2] K. Sugii and M. Yamada, "Steel panel shear walls with and without concrete covering," in Proceedings of the on CD-ROM, 11th world conference on earthquake engeering, vol. 65, pp. 10-32, Acapulco, Mexico, April 2011.

[3] R. G. Driver, L. Kulak, A. E. Elwi, and D. J. L. Kennedy, "FE an simplified models of structural engrg," ASSCE, vol. 12, pp. 24-40, 2010.

[4] J. W. Berman, O. C. Chelik, and M. Brouneau, "Comparing Hysteresis Behavior of light-Gauge steel plate shear walls and and braced frame," Engineering structure, vol. 14, pp. 201-221, 2011.

[5] P. A. Timler and G. L. Kulak, "Experimental study of steel plate shear wall," Structural engineering report," University of Alberta, Canada, vol. 10, no. 114, pp. 89-111, 2003.

[6] R. G. Driver, G. L. Kulak, A. E. Elwi, and D. J. L. Kennedy, "FE and simplified models of steel plate shear wall," Journal of Structural Engineering, vol. 124, no. 2, pp. 121-130, 1998.

[7] A. S. Lubell, H. G. L. Prion, C. E. Ventura, and M. Rezai, "Unstiffened steel plate shear wall performance under cyclic loading," Journal of Structural Engineering, vol. 126, no. 4, pp. 453-460, 2000.

[8] M. Elgaaly and Y. Liu, "Analysis of thin steel plate shear walls," Journal of Structural Engeering, vol. 123, no. 11, pp. 14877-21496, 2008.

[9] A. Astane-Asl, "Seismic behavior and design of steel shear walls," Structural steel educational council technacal information and product service, vol. 52, pp. 222-240, 2015.

[10] A. Rahai and F. Hatami, "Evaluation of composite shear wall behavior under cyclic loading," Journal of construction steel research, vol. 65, pp. 1528-1537, 2017.

[11] A. Astaneh-Asl and Q. Zhao, "Cyclic behavior of traditional and an innavative composite shear wall," Report No. UCBSteel-01/2002, Department of Civil Environmental Engineering university of California, Berkeley, CA, USA, 2017.

[12] F. Hatami and S. M. R. Sohri, "Evaluation of shear plate thickness variations on composite shear wall behavior," Journal of structure and steel, vol. 3, no. 4, pp. 10-25, 2008.
[13] S. Hadipour and J. Razaghi, "Assessment and comparison of loading capacity and ductility behavior of steel shear wall and composite (C-SPW) using finite element method (ANSYS application)," in Proceedings of the fifth international conference of earthquake engineering, Spring, Tehran. Iran, May 2007).

[14] Y. Takanashi, T. A. Takemoto, and M. Tagaki, "Experimental study on thin steel shear walls and particular bracing under alternative horizantal load," Preliminary report, IABSE, Symposium On resistance and ultimate deformability of structure acted on by well define repeat loads, vol. 12, pp. 63-80, 2001.

[15] H. Minura and H. Akiyama, "Load-Deflection relationship of earthquake-resistant steel shear walls with a development diagonal tension field," Transactions of AIJ, Japanese, vol. 23, pp. 150-170, 1998.

[16] V. Caccese and M. Elgaaly, "Experimental study of Thin steelplate shear walls under cyclic load," Journal of Structural Engeering, vol. 36, pp. 119-140, 1993.

[17] E. Alavi and F. Nateghi, "Experimental study of diagonally stiffened steel plate shear walls," Journal of Structural Engineering, vol. 139, no. 11, pp. 1795-1811, 2013.

[18] M. M. Alinia and M. Dastfan, "Cyclic behaviour, deformability and rigidity of stiffened steel shear panels," Journal of Constructional Steel Research, vol. 63, no. 4, pp. 554-563, 2007.

[19] F. Li and H. Li, "Cyclic test of diagonally stiffened steel plate shear wall," Journal of Constructor Steel Reservoir, vol. 41, no. 1, pp. 57-62, 2009.

[20] S. Maleki and M. Tabbakhha, "Numerical study of slotted web reduced flange moment connection," Journal of Constructional Steel Research, vol. 63, no. 9, pp. 86-100, 2011.

[21] S. M. S. Kolbadi, H. Piri, A. Keyhani, S. M. Seyed-Kolbadi, and M. Mirtaheri, "Nonlinear seismic performance evaluation of flexural slotted connection using endurance time method," Shock and Vibration, vol. 2020, no. 1, pp. 1-15, 2020.

[22] M. HajiMirsadeghi, M. Mirtaheri, and A. Peyman Zandi, "Experimental and numerical analysis of a new modular steel shear wall system," Thin-Walled Structures, vol. 61, no. 7, pp. 12-37, 2017.

[23] Iran National Building Regulations, "National building regulations office," Ministry of Roads and Urban Development, Deputy for Housing and Construction, Ministry of Road and Urban Development, Tehran, Iran, 2013. 